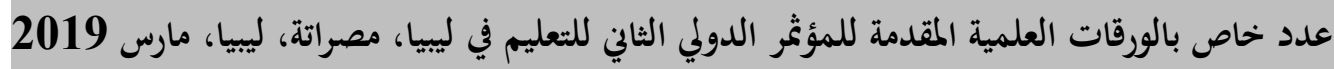

\title{
استخدام نظام التعليم الالكتروبي لرفع مستوى الأداء في مؤسسات التعليم العالي بليبيا
}

$$
\text { د.عقيل محمد عقيل }
$$

ملخص البحث:

أصبح العالم يعيش ثورة علمية وتقنية كبيرة كان لها تأثير على مختلف جوانب الحياة، وأصبحت مؤسسات التعليم العالي مطالبة بالبحث عن أساليب ونماذج تعليمية جديدة لمواجهة العديد من التحديات على المستوى العالمي منها زيادة الطلب على التعليم، مع نقص عدد المؤسسات ذات الجحودة التعليمية، وزيادة كم المعلومات في جميع فروع المعرفة المختلفة فضلاً عن ضرورة الاستفادة من التطورات التقنية في بحال التربية والتعليم، ليظهر نموذج التعليم الالكتروني ليساعد المتعلم على التعلم في المكان والزمان المناسبين له من خلال محتوى تفاعلي يعتمد على الوسائط المتعددة، وبالتالي فإن التعليم الالكتروني يعد نمطاً جديداً من أنماط التعليم، فرضته التغيرات العلمية والتقنية التي يشهدها العالم، ولم تعد الطرق والأساليب التقليدية قادرة على مواكبتها، ولذا أصبحت الحاجة ملحة لتبني نوعاً آخر من أنواع التعليم وهو التعليم

$$
\text { الإلكتروني الذي يعتبر من الابحاهات الجديدة. }
$$

وفي هذه الدراسة تم توضيح كيفية الاستفادة من التجارب العالمية في تطبيق التعليم الالكتروين في مؤسسات التعليم العالي من خلال دراسة تطبيقات التعليم الالكتروني في مؤسسات التعليم العالي الدولية، ومن خلال الدراسة التحليلية المقارنة تم استخلاص أوجه التشابه والاختلاف وبالتالي وضع تصور مقترح لتطبيقات التعليم الالكتروني في مؤسسات التعليم العالي بليبيا من خلال نتائج الدراسة المقارنة، وقد تم استخدام المنهج المقارن في هذه الدراسة بمدخله الوصفي التحليلي من خلال الوصف الشامل للظاهرة وتحليل المعلومات والبيانات المتصلة بموضوع الدراسة . الكلمات المفتاحية: جودة التعليم العالي، التعليم الالكتروني، تطبيقات التعليم الالكتروني، التجارب العالمية في تطبيق التعليم الالكتروني ، التطورات التقنية في بحال التعليم العالي. 
يعاني التعليم العالي في ليبيا من أزمة عميقة تفاقمت بسبب الظروف القاسية التي تمر بها بلدنا من الأزمات السياسية

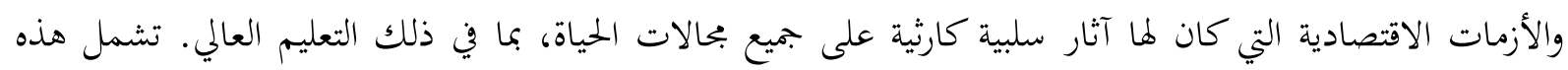
الأزمة الحادة جميع عناصر التعليم العالي(عضو هيئة التدريس والطالب والمنهج الدراسي والنظام التعليمي ووسائله والمتطلبات التعليمية والأنظمة الإدارية). أحد مظاهر هذه الأزمة هو ضعف تأهيل أعضاء هيئة التدريس بسبب غياهي

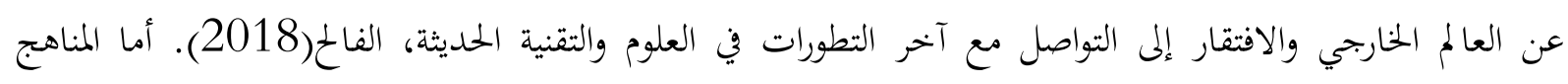
الدراسية يقوم النظام التربوي بشكل أساسي على مبدأ التلقين وتراكم المعلومات في عقول الطلاب دون الدخول في حوار ومناقشة وتحفيز الرغبة في التعلم مع الاعتماد على أساليب تدريس غير فعالة، وهناك نقص واضح في المتطلبات التعليمية

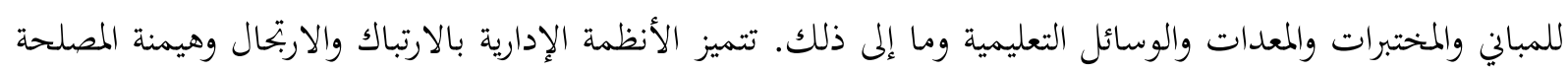
الشخصية لصناع القرار على المصلحة العامة. التحدي الآخر الذي يواجه بحتمعنا بشكل عام والتعليم العالي بشكل خاص هو دخول عالم عصر المعلومات والانفجار الهائل في المعرفة. يتطلب هذا التحدي بذل جهود استثنائية لمواكبة هذا التطور الهائل لتقنية المعلومات والاتصالات لسد الفجوة بين جامعاتنا والجحامعات الدولية المتقدمة. سنركز في هذه البحت على جانب واحد يمكن أن يساهم في تحسين التعليم العالي والحدد من الفجوة المعرفية والفنية بين بحتمعنا والبحتمعات المتقدمة، وهو نوع حديث من التعليم، ألا وهو التعليم الإلكتروين.

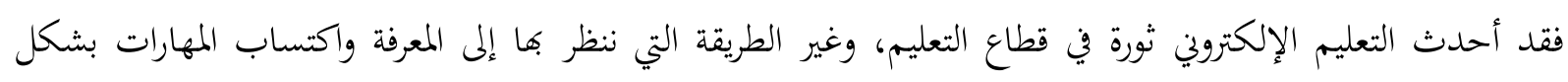
كامل بفضل التقنية التعليمية الحديثة، وأصبحت أدوات وتقنيات التعليم الإلكتروي أكثر فأكثر ـ واليوم فهم يزودون المتعلمين بتجربة تعليمية أكثر إثارة للإعجاب وأكثر فاعلية باستخدام تقنية الحاسب كأداة لتوفير الدعم الأساسي لعملية

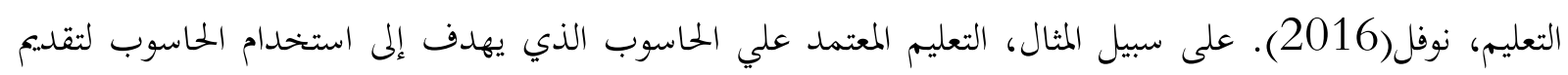

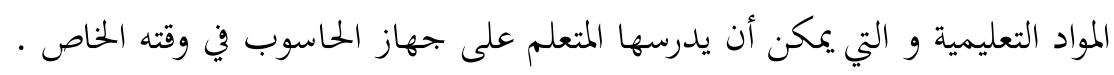
حيت أتاح التوافر الواسع النطاق لتقنية الحاسب والاتصالات السلكية واللاسلكية توزيع المواد التعليمية في جميع أنحاء العالم، أسرع من أي وقت مضى، مع مرونة أكبر بكثير، ومع زيادة إمكانية الوصول إلى عملية التعلم، لدرجة أنه يوجد

$$
\text { اليوم تحول نحو ما يسمى التعليم الإلكتروني، نوفل(2016). }
$$

2. 2 تقنية التعليم الالكتروبن:

التعلـيم الإلكـتروي هـو بيئـة تعليميـة يـتمكن فيهـا المتعلمـون والمعلمـون مسن أداء مهــام شـبيهة بالفصـول الدراسـية، الفــالح(2018): تـوفر الويــب الوسـيط وتسـتوعب البيئسة التعليميـة؛ يقـوم المعلمـون بتصـميم بتربــة الـتعلم مــن خـلال إعـداد المـواد التعليميـة، واتخـاذ القـرار بشـأن المـنهج التربـوي، وتحديـــ الأهـداف التعليميـة للـدورة وكيـف يـتم

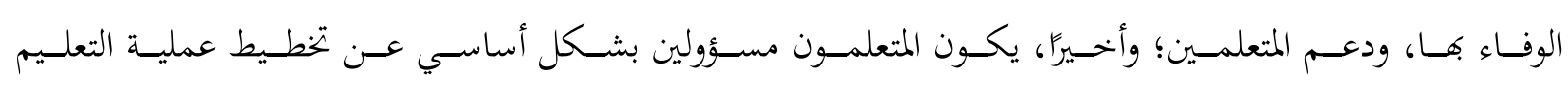

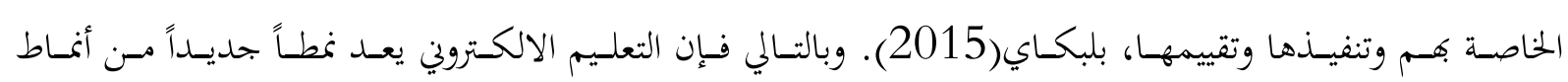




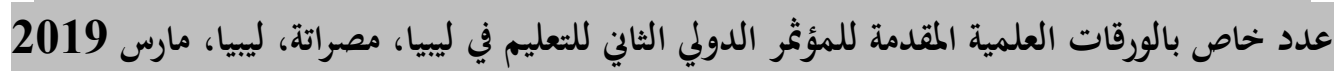

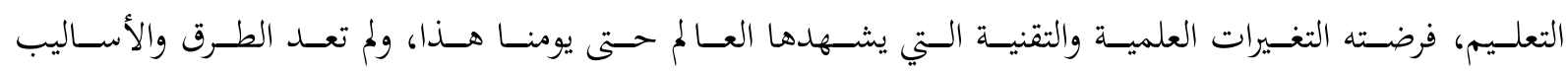

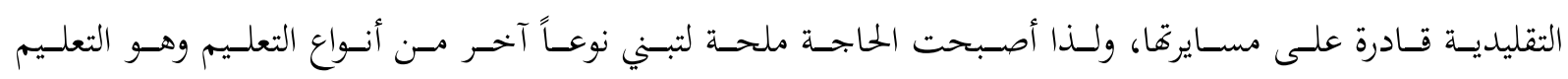

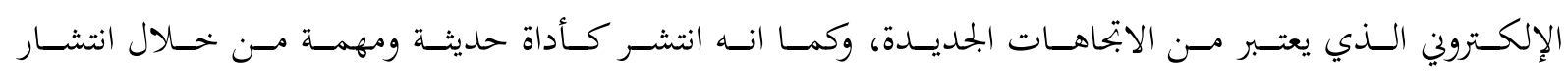

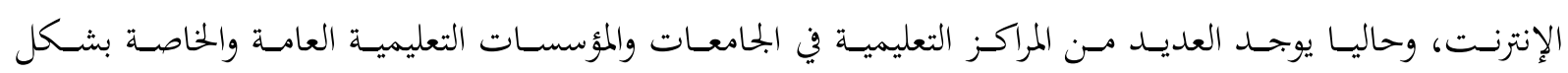
عام، التي تعتمد عليه كوسيلة تعليم مرنة، وكذلك وسيلة تعليم عن بعد.

\section{3. مشكلة البحث:}

اذا كانت تقنية المعلومات قد أحدثت تغيرات جذرية في مختلف جوانب الحياة المعاصرة، فان قطاع التعليم عامة والتعليم العالي خاصة يجب أن يكون اكثر استجابة لهذه المتغيرات الهائلة والتطورات المتسارعة، ذلك لأن مخرجات قطاع التعليم العالي ما هي إلا مدخلات لقطاعات أخرى كعناصر عمل. فقطاع التعليم الجامعي يستدعي التوسع الكبير في استخدام تقنية المعلومات و خاصة منها تفعيل نظام التعليم الالكتروني وذلك لما يحققه من عوائد ومزايا في مجال التعليم الجامعي وضمان الجحودة والارتقاء بمستوي التأهل والكفاءة والخبرة لجميع الموارد البشرية. وفي ليبيا تعاني المؤسسات التعليمية الجامعية من فقر في استخدام تقنية التعليم الالكتروني بجانب ضعف استجابة الطلاب مع النمط الجحديد من التعليم وتفاعلهم معه، وندرة أعضاء هيئة التدريس ممن يجيدون "فن التعليم الالكتروني"، وإنه من الخطأ التفكير بأن جميع الأساتذة يستطيعون أن يساهموا في هذا النوع من التعليم. إضافة إلي ذلك هناك مشكلة ترتبط بوعي أفراد المحتمع بهذا النوع من التعليم، والحاجة المستمرة لتدريب ودعم المتعلمين والإداريين في كافة المستويات، حيث أن هذا النوع من التعليم يحتاج إلى التدريب المستمر. وفي هدا الورقة ندرس واقع التعليم الالكتروين ونقترح اطار لاستخدامه في التعليم العالي، ويتمثل الهدف من هذه الدراسة في التعرف على الاستراتيجيات والآليات التي من خلالها يتم تفعيل النظام الالكتروني بالجامعات الليبية حتي يساعد على رفع وتحسين الاداء بها.

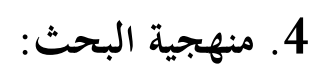

المنهجيـة المسـتخدمة في البحـث هـي المـنهج المقـارن، للاتجاهـات العالميـة في تطبيقـات التعلـيم الالكـتروني وجوانـب الاستفادة منها في مؤسسات التعليم العالي من خلال دراسة وتحليل الحقائق والمعلومات والبيانات والإحصائيات المتصلة بموضوع الدراسة في ضوء القوى والعوامل الثقافية، وبالتالي التحليل الثقافي المقارن للعناصر موضع البحث بجوانبها المختلفة واستخحلاص أوجـه التشـابه والاختلاف المرتبطة بتطبيقات التعليم بين دول المقارنة. والسبب في اختيـار المنهج المقـارن المسـاعدة في فهم التجارب العالمية في تطبيقات التعليم الالكتروين مـن خلال توزيعها على ملخصات للمقارنة تشمل 


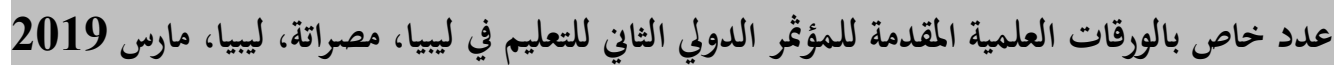

الجوانب المتشابهة والمختلفة بينها ومعرفة إيجابيّات وسلبيّات الدراسات التي تعتمد على تطبيق المنهج المقارن، والتي تساهم في استنتاج العلاقات والربط بين التجارب العالمية في تطبيقات التعليم الالكتروني.

\section{5. الطلب على برامج وخدمات التعليم الإلكتروين :}

أن ارتفاع شعبية التعليم الإلكتروني لا يظهر أي بوادر على التباطؤ. في الواقع واستناداً إلى إحصائيات التعليم الإلكتروني، فإن مستقبل صناعة التعليم الإلكتروي أكثر إشراقاً من أي وقت مضى:

- ـ في عام 2014، تم تقدير أن حوالي 112 مليار دولار سيتم إنفاقها على التعلم الإلكتروني في جميع أنحاء العالم خلال العام 2015. وسوف يتضاعف خلال السنوات القادمة. أنظر الشكل رقم 1 يوضح الأنفاق العالمي علي التعليم الإلكتروين، Medved (2014).

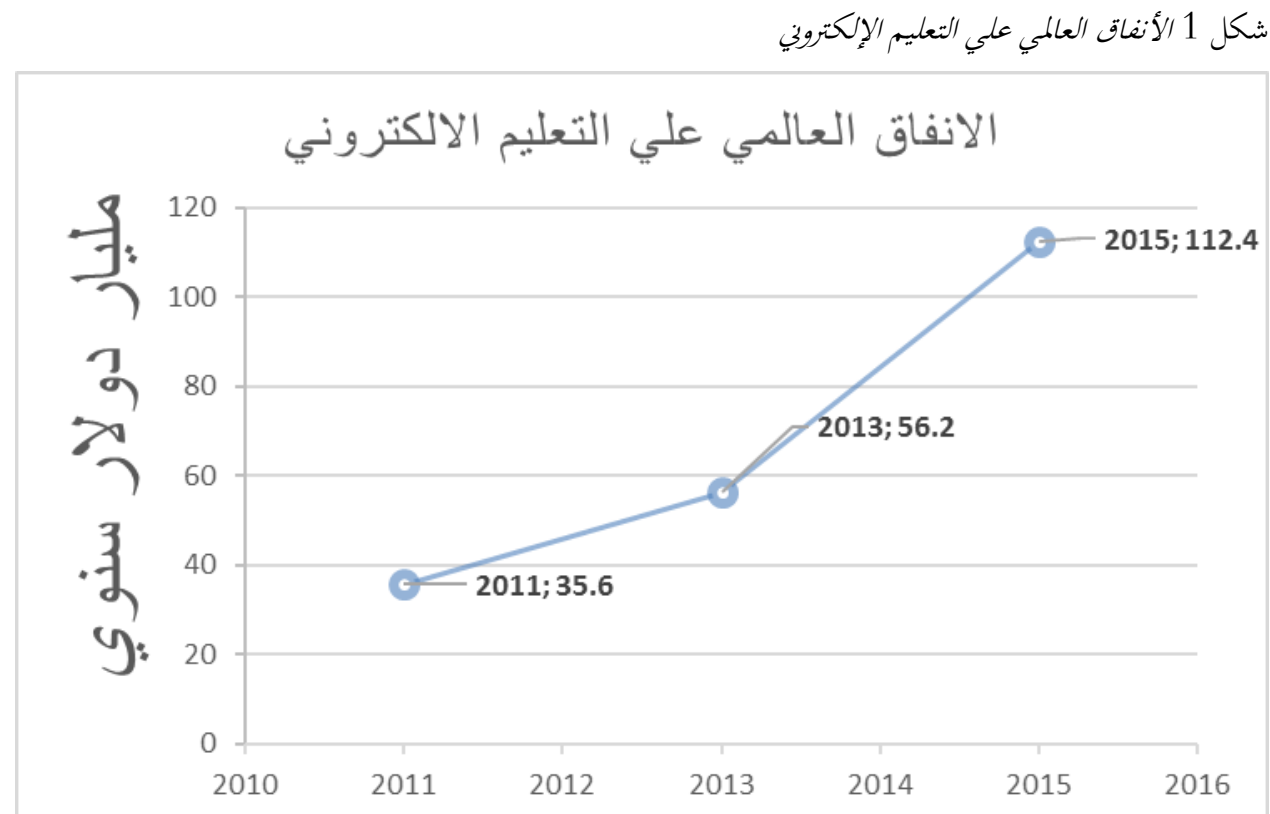

- - تشير الشركات الآن إلى أن التعليم الإلكتروين هو ثاني أفضل أسلوب تدريب يستخدمونه. ولا يعد ذلك مفاجئًا نظرًا لأن التعليم الإلكتروني ينقذ الأنشطة التجارية بنسبة 50٪ على الأقل عندما يحل محل التدريب التقليدي القائم على المدرب مع التعليم الإلكتروين. ناهيك أن التعليم الإلكتروني يقلل مدة التعليم بنسبة تصل إلى 60٪ 


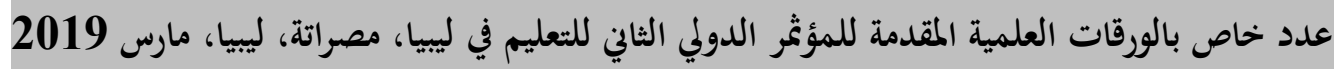

- - التعليم الإلكتروني هو أيضا صديق للبيئة. وقد وجدت الدراسات الحديثة التي أجرتا جامعة بريطانيا المفتوحة أن التعليم الإلكتروني يستهلك طاقة أقل بنسبة 90٪ من الدورات التقليدية. يتم تقليل كمية انبعاثات ثاني أكسيد

$$
\text { الكربون (لكل طالب) بنسبة تصل إلى 85٪ }
$$

-

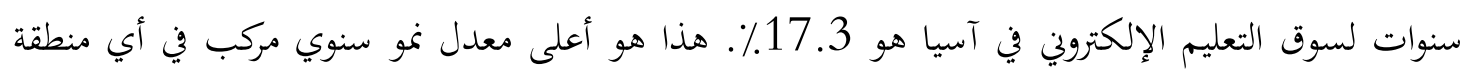

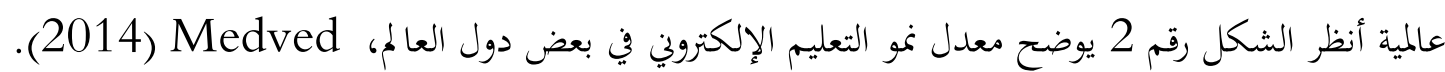

$$
\text { شكل } 2 \text { معدل نمو التعليم الإكتتروني في بعض دول العالم }
$$

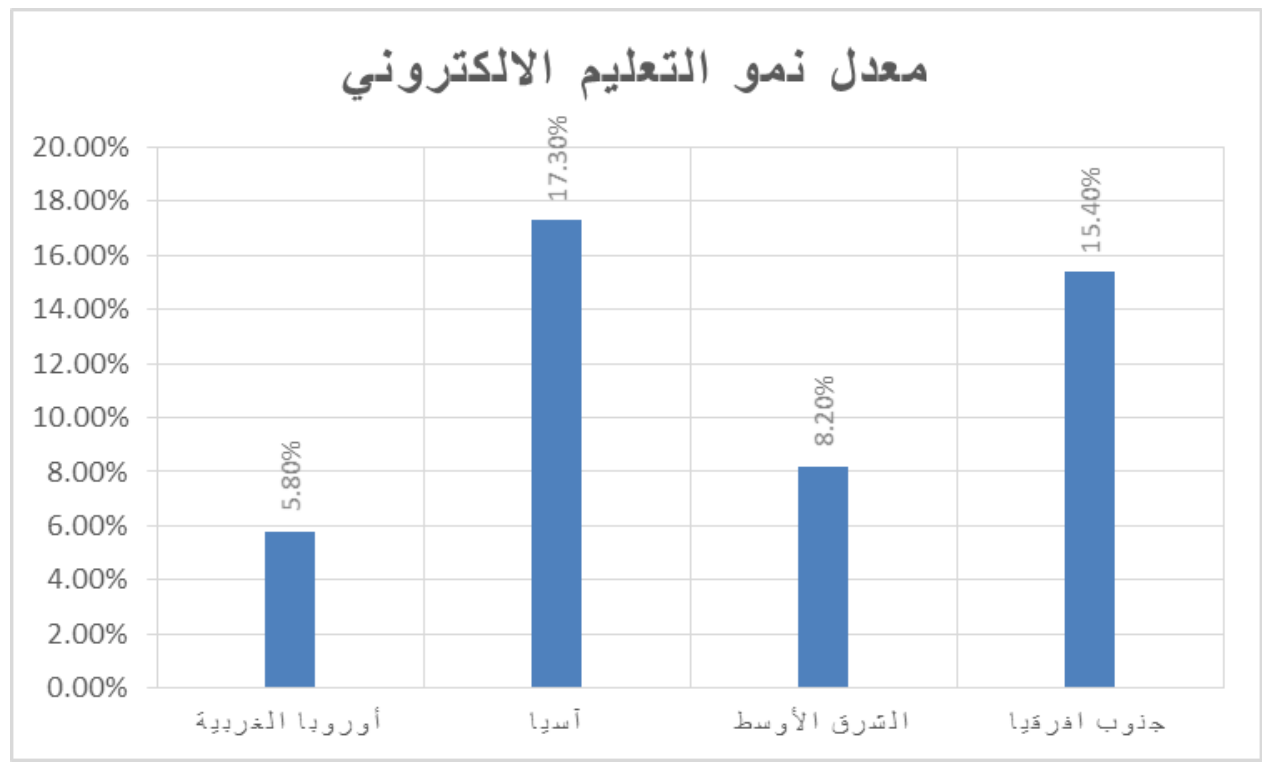

- وفقاً لتقرير أصدرته شركة IBM، فإن الشركات التي تستخدم أدوات واستراتيجيات التعليم الإلكتروني لديها القدرة على زيادة الإنتاجية بنسبة تصل إلى 50٪، Medved (2014). مقابل كل دولار تنفقه هذه الشركة، يقدر أهما ستحصل على إنتاجية بقيمة 30 دولارًا.

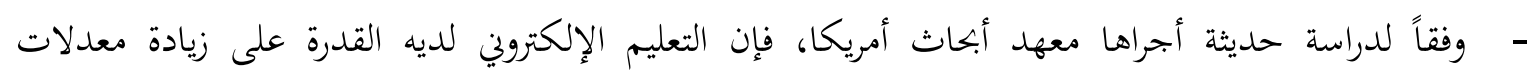

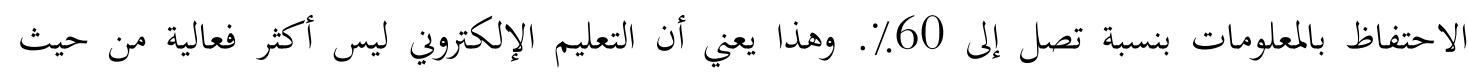
التكلفة فحسب، بل إنه أيضًا أكثر فعالية من حيث مقدار المعرفة التي يتم اكتساهما بالفعل أثناء عملية التعليم.

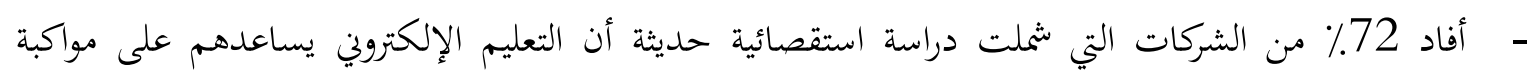

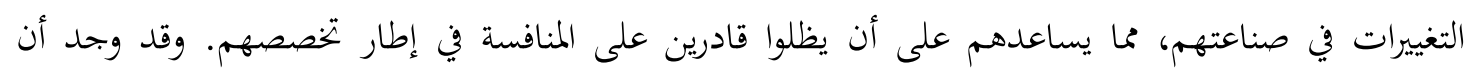




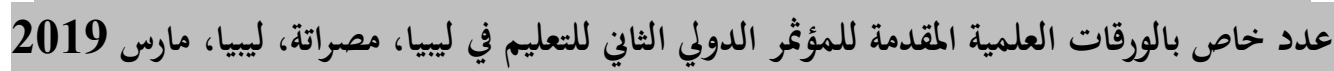

الشركات والمؤسسات التي لديها ثقافة تعلم قوية كانت أفضل في سوقها من أولئك الذين لم يفعلوا ذلك. على سبيل المثال، فإن هذه المنظمات أكثر بنسبة 46٪ لتكون رائدة في صناعتها، لاحظ زيادة بنسبة 34٪ في قدرقا على الاستجابة لاحتياجات العملاء، و 17٪ أكثر عرضة لتصبح رائدة في حصة السوق، Medved .(2014),

\section{6. تطبيقات التعليم الالكتروين في بعض دول العالم:}

نظرا للأهمية التي يعول فيها على التعليم الالكتروني لإحداث قفزة وتطور نوعي وكمي في عملية التعليم ومخرجاته وتوجهاته، فقد تناولت الكثير من الدراسات فاعلية هذا النوع من التعليم، وفيما يأتي استعراض لبعض من هذه التطبيقات للتعليم الالكتروني في دول مختلفة من العالم، وقد روعي التنوع في اختيار الدول ما بين متقدمة كدول الاتحاد الاوروبي والولايات المتحدة الامريكية، وأخري نامية مثل سنغافورة وكوريا الجنوبية.

رؤية الدولة 1 بحارب تطبيق التعليم الإلكتروفي في بعض دول العالم

تعتبر كندا من الدول الرائدة في التعلم الإلكتروني والتعليم عن بعد، وقد بدأت اللجنة الاستشارية للتعليم الإلكتروني ببرنامج أطلقت عليه اسم (طفرة التعليم الالكتروني، التحدي الكندي)، ويركز هذا المشروع علي الكندية تسريع استخدام التعليم الإلكتروني في التعليم عن طريق زيادة المرونة ورفع كفاءة البرامج التعليمية الإلكترونية في المؤسسات التعليمية الكندية، وتعتبر كندا مثالاً متميزاً لدمج التعليم الإلكتروني في التعليم، .(2016)Dutto

في بريطانيا، ظهرت ما يسمى الشبكة القومية للتعليم، حيث تم ربط أكثر من 32000 مدرسة بالإنترنت وكان هناك 9 ملايين طالب و 450 ألف معلم. ستؤدي عملية التقديم إلى تقليل الأعمال الورقية، وسيتم البريطانية تدريب المعلمين ومراقبة مستويات أدائهم، وسيتم تدريب وبتهيز 10000 جهاز حاسوب. سيتم إرسال المعلومات والمواد التعليمية من المعلم إلى الحاسوب المحمول. سيتم أيضًا ربط المواقع التعليمية المختلفة بالشبكة القومية، الراشد(2017).

لا تزال من أقل الدول صرفاً علي هذا النوع من التعليم مقارنة بالدول الأوروبية الأخرى، ولا زال التركيز علي التعليم التقليدي مع الإفادة من بعض مجالات التعليم الإلكتروني، وتمتلك ألمانيا مشروعاً متطوراً للربط 


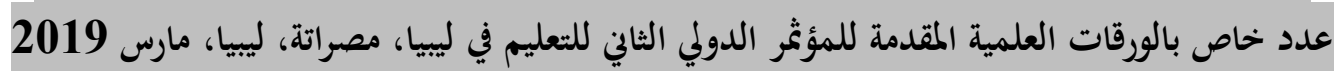

اللاسلكي بين الوحدات التعليمية، ومن ضمن مهام ذلك المشروع تشجيع وسائل التعليم الحديثة عبر تلك الشبكات، والإفادة من تلك الشبكات في توفير المعلومات الوظيفية، وهو ما تم تطويره ليشمل التعليم عن بعد، (2017) Asunka

تعتبر السويد من أكثر الدول تقدماً في بحال التعليم الإلكتروني، فهي تمتلك بنية تحتية قوية وتستخدم تقنيات عالية، وقد سبقت كثير من الدول في هذا المحال، لهذا تعتبر رائدة وقيادية في هذا المضمار، وتهتم الحكومة اهتماماً كبيراً بالتعليم الالكتروني وتطوير التعليم التقليدي. الهيئة السويدية للتعليم عن بعد التي السويدية أنشئت عام 1999 م، هذه الهيئة تدعم التعليم الإلكتروني والتعليم عن بعد، الراشد(2017). تؤكد رؤية التعليم الإلكتروني في سنغافورة إلى أهمية القوي البشرية، فالإنسان هو رأس المال والمهارات والمعارف من خلال التعليم والتدريب، وتقوم الشركات السنغافورية بدعم ما يقرب من 20-25٪ من ميزانية التدريب على التعليم الإلكتروين. ولا يمكن إغفال النتائج التي حققها التعليم الإلكتروني في سنغافورة سنغافورة في بحال محو الأمية والتي فاقت بنسبة 71\% على التعليم التقليدي، الراشد(2017).

قدمت كوريا الجنوبية استراتيجية للتعليم الالكتروني في بحالات البحوث والتعليم والخدمات ليكون بمثابة تعلم للمجتمعات المحلية لتشمل المعلمين والمتعلمين والخريجين بأعدادهم للانخراط في التعلم مدى الحياة. بدأت تطبيقات التعليم الالكتروني في كوريا الجنوبية منذ مدة طويلة، حيث أنشئت الجامعات الإلكترونية مثل جامعة كوريا الوطنية المفتوحة (نو) لتوفير تعليم على الإنترنت وأنشطة التعلم. كوريا حققت \%5\% من الجامعات والكليات بعض الجوانب الايجابية في بحال التعليم الإلكتروني، فشكلت فرق الجنوبية التعليم الإلكتروني الخاص في معظم الجحامعات. وبينت النتائج المستخلصة من هذه الدراسة والمرتبطة بكل من المعلمين والمتعلمين على حد سواء، كما تطرقت إلى نظم الدعم ذات مغزى والفرص المتاحة للمشاركة بنشاط في برامج التعليم الإلكتروني، كما ان تطبيقات التعليم الالكتروني في الجحامعات الخناصة والكليات الخاصة يفوق نظيرتا في الجامعات الحكومية، بجانب الجامعات المتخصصة في التعليم عن بعد من التعليم، كما أبرزت أن الجحامعات بجهزة بالدعم التقني مثل البنية التحتية والمناهج التشغيلية، Jung (2017). تم وضع الخطة الوطنية لتقنية المعلومات، وقد تضمنت تلك الخطة سبعة أهداف رئيسة ركز الهدف الرابع منها علي أهمية التوظيف الأمثل لتقنية المعلومات في التعليم والتدريب بجميع المراحل، وقد ظهرت بحموعة السعودية من المؤشرات والمبادرات حول التعليم الإلكتروني والتي تبين قناعة مؤسسات التعليم بالتعليم الإلكتروين في المملكة ومنها: مشروع وطني، ومشروع التعلم الإلكتروني، ومشروع المدارس الرائدة، ومبادرات المدارس الأهلية(الفصول الذكية، الفصول الإلكترونية)، ومبادرات الجامعات لاستخدام أنظمة إدارة التعليم 
عدد خاص بالورقات العلمية المقدمة للمؤثم الدولي الثاني للتعليم في ليبيا، مصراتة، ليبيا، مارس 2019

الإلكتروني، ومشروع تدريس الحاسب في المدارس الحكومية، ومشروع برنامج 'معارف'، لزيادة وعي المدارس بأهمية الحاسب كأداة تعليمية فعالة وزيادة الاعتماد عليه في التعليم والإدارة. تستخدم جامعة الملك عبد العزيز أساليب التعليم الإلكتروني منذ فتر ة طويلة، ولديها أكبر مكتبة إلكترونية في المملكة تحتوي على 16 ألف كتاب إلكتروني، ووقعت وزارة التعليم العالي في أواخر عام 2006 مع شركة ميتيور الماليزية عقد تنفيذ المرحلة التأسيسية الأولى للمركز الوطني للتعليم الإلكتروني و التعليم عن بعد، الذي يهدف إلى إيجاد نواة لحضانة مركزية للتعليم الإلكتروبي و التعليم عن بعد لمؤسسات التعليم الجامعي و توحيد جهود المؤسسات الساعية لتبني تقنيات هذا النوع من التعليم، الصالح(2017).

طبقت وزارة التربية والتعليم بدولة الكويت التعليم الالكتروين في جميع المراحل التعليمية، وذلك بهدف إيجاد بيئة تقنية للتعليم من خلال عدة طرق، أولها: إعداد برامج إلكترونية تعليمية معدة مسبقاً للمناهج الدراسية، وإعداد فصول إلكترونية بجهزة بأفضل الوسائل التقنية مع توفير شبكة إلكترونية (إنترنت)، الكويتية وإعداد هيئة تدريسية واعية ومثقفة إلكترونيا، حيث طبق المشروع أولا علي نطاق تجريبي كما تم وضع خطة تنفيذية لبرنامج تدريبي بالتعاون مع مؤسسات القطاع الخاص، بالإضافة إلي عمل برامج توعية شاملة لأولياء الأمور والعاملين في الحقل التربوي من خلال وسائل الاتصال المختلفة المرئية والمقروءة والمسموعة، كمدف توعية الجميع بالتجربة قبل تطبيقها، حسن(2018).

قامت وزارة التربية والتعليم بالشروع في تنفيذ مشروع جلالة الملك "مد" ويهدف هذا المشروع الي تطوير المنظومة التعليمية، حيث انتهجت الوزارة تطبيقها لهذا المشروع الحيوي استراتيجية التطبيق التجريبي المتدرج بدءا بعدد من المدارس الثانوية التي تم اختيارها بعناية لتصبح مدارس رائدة في تطبيق التعليم الإلكتروني، البحرينية ومن ثم تبعها بعد ذلك إجراء تقييم دقيق للتجربة لتعميمها علي جميع المدارس، بن فحوص(2013). على سبيل المثال تفعيل نظام البيئة التعليمية، الذي تم بثه على شبكة جامعة قطر منذ عام 2007م، ومن المعروف أن التعليم الإلكتروبي بواسطة نظام البيئة التعليمية يعمل علي توفير الوقت والجها على الطالب والأستاذ، ويوفر أيضاً من نفقات الجامعة في أمور كثيرة، كما أنه نظام فعال في العملية التعليمية، من حيث القطرية التشجيع على الابتكار، وتنشيط العقل والفكر وإبداء الرأي ...إخ، كما أنه نظام يوفر التواصل المضمون والآمن بين الطالب والأستاذ في كل وقت وفي كل مكان طالما توفر الإنترنت لمما ويعتبر نجاح جامعة قطر في التعامل مع هذا النظام مؤشر جيد فيما يتعلق بجودة التعليم الالكتروين الذي أثبت فعاليته الكبيرة في تحسين جودة التعليم، من أجل الوصول إلى العديد من الأهداف المتمثلة، لازار(2013).

الإمارتية تبنت وزارة التربية والتعليم والشباب مشروع تطوير مناهج لتعليم مادة الحاسب الآلي بالمرحلة الثانوية، وقد 


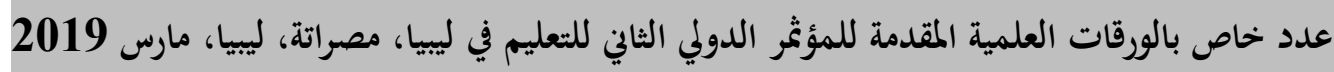

لقيت هذه التجربة قبولاً لدى الطلاب وأولياء الأمور، وفضلاً عن الأهداف التي حددقا الوزارة فقد أسفرت التجربة عن نتائج إيجابية متعددة، الراشد(2017).

قامت وزارة التربية والتعليم في السلطنة في إطار تطوير التعليم بإعداد خطة شاملة وطموحة تسعى من سلطنة خلالها إلى الانسجام مع المتطلبات التنموية للسلطنة، وقد تم إنشاء مراكز مصادر التعلم في كل مدرسة عمان من مدارس التعليم الأساسي في السلطنة وتم تزويدها بأحدث الاجهزة التعليمية والتقنية خاصة الحاسب الآلي.

تقوم الرؤية المصرية لتحقيق تطبيقات التعليم الإلكتروني من خلال مفهوم الجحودة فقامت التطبيقات في التعليم الالكتروني علي نفس المرتكزات التي أقرتا هيئة الجودة المصرية، نتيجة لتلك الرؤية تزايدت تطبيقات التعليم الالكتروني في مؤسسات التعليم العالي في مصر، فتم إنشاء المركز القومي للتعليم الإلكتروني في عام المصرية 2005 كأحد المشروعات الرئيسية الممولة من مشروع تطوير نظم وتقنية المعلومات في التعليم العالي2ICTP. وفي عام 2008 تم إنشاء الجامعة المصرية للتعليم الإلكتروفي 2008 بدعم من صندوق تطوير التعليم برئاسة بحلس الوزراء كأول جامعة مصرية تتبنى مبدأ التعليم الإلكتروني في تقديم خدمات تعليمية على أعلى مستوى جودة، الفالح (2018).

في إطار إرساء منظومة متكاملة للتعليم عن بعد تفتح المحال أمام جميع التونسيين و تكريسا لمبدأ التعليم مدى الحياة و ثقافة التكوين المستمر، تمّّ إحداث جامعة تونس الافتراضية و الاستجابة للتحديّات المتمثلة في تزايد عدد الطلبة بالتعليم العالي، و ذلك بالقيام بعملية تخفيف تدريجي بالشعب ذات الأولوية لمؤسسات التكوين الحضوري و تحديث شعب التكوين الموجودة باستعمال التقنيات الرقمية، و العمل على أن يشمل التعليم العالي أكبر عدد من الجمههور المستهدف خارج دائرة الطلبة العاديين بتسيدا لمبادئ التعلم التونسية الذاتي و التكوين المستمر مدى الحياة و إتاحة الفرصة لكل تونسي للتعليم المتواصل إثراء لمعارفه أو طلبا للارتقاء المهني. و بذلك يبرز دور جامعة تونس الافتراضية فاعلا في تطوير منظومة التعليم العالي و في تحسين الجودة. فقد سعت الجامعة منذ إحداثها إلى بلوغ الأهداف الرامية إلى تحقيق نقلتها النوعية من طور الانطلاق إلى مستوى المنظومة المتكاملة و ذلك بالعمل على: تركيز البنية التحتية التقنية و تطويرها، تكوين الأساتذة و التقنيين، إنتاج المحتوى التكويني غير الحضوري، تأمين أنشطة التكوين غير الحضوري، تنمية الشراكة الجامعية مع الخنارج، نوفل(2016).

اعتمدت وزارة التربية والتعليم الأردنية في عام 2002 م، بالتنسيق مع وزارتي التخطيط وتقنية المعلومات والاتصالات سياسة وطنية للتعليم الإلكتروني من خلال إنشاء شبكات المعرفة الوطنية، حيث استخدمت 


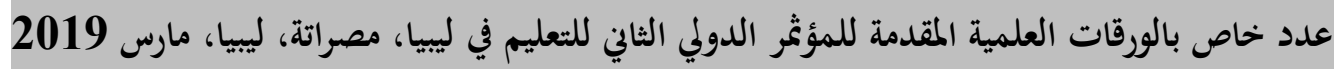

تقنية المعلومات والاتصالات كقاعدة للتحول إلي نظام التعلم الذي يعتمد علي تطوير قدرة التعلم الذاتي والتفكير النقدي بدلا من نظام التعليم التقليدي الذي يعتمد التلقين من قبل المعلم بشكل أساسي، الصالح). (2017).

أطلقت الجزائر ما يسمى بالمدرسة الرقمية لطلاب المدارس الإعدادية والثانوية من خلال وضع برنامج خاص على الإنترنت يستهدف في البداية أولئك الذين اجتازوا امتحانات الشهادة الثانوية أو شهادة التعليم الأساسي. هذه المدرسة الافتراضية هي حل شامل ومتكامل يسمح لجميع الأطراف الفاعلة في عملية التعليم في التعليم عن بعد، والثاني الأكثر أهمية لأنه موجه بشكل خاص للتلاميذ وأولياء أمورهم والمؤسسات التعليمية على حد سواء، والتي هي "تعليمك". في نفس البرنامج، أدخلت مؤسسة عباد مدرسة افتراضية تسمح للطلاب الذين يحضرون أو يحضرون المدرسة العامة بالتسجيل في الامتحان. تتطابق المواد التي يتم تدريسها في هذه المدرسة الافتراضية مع البرنامج الرسمي الذي وضعته وزارة التعليم. ويعود الجزائرية تاريخ الإطلاق إلى 4 سنوات. يمكن لأي طالب في المرحلة النهائية الرابعة الدخول إلى الموقع والتسجيل حيث يجد 300 درس للنهائي و 300 درس للمتوسط، بالإضافة إلى 3000 تمرين مع التصحيح والتوضيح، ويمكن للطالب الاتصال بأستاذ المقال على هذا البرنامج للحصول على تفسيرات، يمكنه أيضًا الاطلاع على مواد الشهادة الثانوية أو امتحانات التعليم الأساسي مع التصحيح. يمكن للوالدين أن يروا

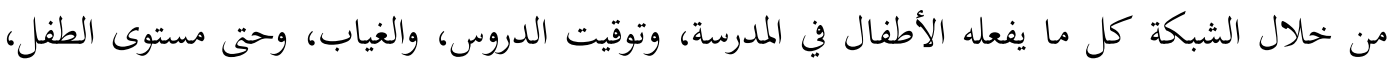
وتعلم جميع النقاط والملاحظات. يمكن للمعلم من خلال مكتب الأستاذ أن يرى قائمة الطلاب والدروس، غراف(2014).

بدأت بحربة اليابان في محال التعليم الإلكتروني في عام 1994 م بمشروع شبكة تلفازية تبث المواد الدراسية التعليمية بوساطة أشرطة فيديو للمدارس حسب الطلب من خلال (الكيبل) كخطوة أولى للتعليم عن بعد، وفي عام 1995م أعدت لجنة العمل الخاص بالسياسة التربوية في اليابان تقريرا لوزارة التربية والتعليم تقترح فيه أن تقوم الوزارة بتوفير نظام معلومات إقليمي لخدمة التعليم مدي الحياة في كل مقاطعة يابانية، وكذلك اليابانية توفير مركز للبربجيات التعليمية، إضافة إلي إنشاء مركز وطني للمعلومات، ووضعت اللجنة الخطط الخاصة بتدريب المعلمين وأعضاء هيئة التدريس في عام 1997، حيث أقرت هيئات التعليم علي هذه التقنية الجديدة، وهذا ما دعمته ميزانية الحكومة اليابانية للسنة المالية 1996 إعداد مركز بربحيات لمكتبات تعليمية في كل مقاطعة ودعم البحث والتطوير في بحال البربجيات التعليمية ودعم البحث العلمي الخاص بتقنيات التعليم الجحديدة، وكذلك دعم جميع الأنشطة المتعلقة بالتعليم عن بعد، وكذلك في دعم توظيف 
عدد خاص بالورقات العلمية المقدمة للمؤثمر الدولي الثاني للتعليم في ليبيا، مصراتة، ليبيا، مارس 2019

شبكات الإنترنت في المعاهد والكليات التربوية لتبدأ بعد ذلك مرحلة جديدة من التعليم الحديث، وتعد اليابان الآن من الدول التي تطبق أساليب التعليم الإلكتروني الحديث بشكل رسمي في معظم المدارس اليابانية، 2017)Jung (20)

وضعت لجنة التطوير الشامل الماليزية للدولة خطة تقنية شاملة تحعل البلاد في مصاف الدول المتقدمة، ومن أهم أهداف هذه الخطة إدخال الحاسب الآلي والارتباط بشبكة الإنترنت في كل فصل دراسي من فصول الماليزية المدارس، وتسمي المدارس الماليزية التي تطبق التقنية في الفصول الدراسية "المدارس الذكية" أما فيما يتعلق بالبنية التحتية فتد تم ربط جميع مدارس وجامعات ماليزيا بعمود فقري من شبكة الألياف البصرية السريعة التي تسمح بنقل حزم المعلومات الكبيرة لخدمة نقل الوسائط المتعددة والفيديو، الراشد(2017).

التجربة الفريدة في استراليا هي في ولاية فكتوريا، حيث وضعت وزارة التربية والتعليم الفكتورية خطة لتطوير التعليم وإدخال التقنية في المؤسسات التعليمية في الولاية بشبكة الإنترنت عن طريق الأقمار الصناعية وتعد تحربة ولاية فكتوريا من التجارب المتميزة علي المستوي العالمي من حيث السرعة والشمولية، الأسترالية الراشد(2017). يتناول البحث الجوانب المتعلقة بالدراسة التحليلية المقارنة للاتحاهات العالمية في تطبيقات التعليم الالكتروني وجوانب الاستفادة منها في مؤسسات التعليم العالي من خلال مقابلة المحاور والعناصر الرئيسة للدراسة بغرض الوقوف علي أوجهه التشابه والاختلاف المرتبطة بتطبيقات التعليم بجانب تفسير أوجه التشابه والاختلاف في ضوء القوى والعوامل الثقافية من خلال ما تبرزه عناصر المقابلة لكل من محاور الدراسة :-

1.7 أوجه التشابه والاختلاف المتعلقة بتطبيقات التعليم الالكتروبي في دول المقارنة. قدم البحث العديد من الجوانب المتعلقة بتطبيقات التعليم الالكتروني مع التركيز علي جانبين هامين في إطار فاعلية المناهج المقدمة أحدهما ارتبط بتنشيط عمليات التعليم والتعلم في مؤسسات التعليم المعاصرة، والآخر يتعلق بالأبعاد والمكونات المرتبطة بتطبيقات التعليم الالكتروني.

1.1 .7 أوجه التشابه المتعلقة باستراتيجيات التعليم الالكتروبي ومعاييره في دول المقارنة. - تشابه كل من دول المقارنة في العديد من الجوانب المتعلقة باستراتيجيات التعليم الالكتروين. - استخدام تطبيقات التعليم الالكتروين جنبا الى جنب مع التعليم التقليدي. 


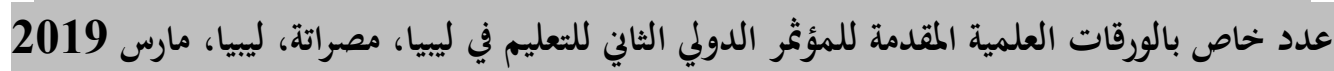

- - تحظى استخدام تقنية التعليم الالكتروين باهتمام الدولة المقارنة وخاصة مؤسسات التعليم الجامعي. المؤسسات التعليمة للاستفادة من دمج التقنية التي تمثل مدخل مهما في عملية الاصلاحات التربوية الحديثة.

\section{تفسير أوجه التشابه المرتبطة باستراتيجيات ومعايير التعليم الإلكتروني.}

يمكن تفسير أوجه التشابه المرتبطة بتطبيقات التعليم الإلكتروني بعوامل ثقافية قوية فالعامل السياسي الراغب في وضع استراتيجيات التعليم الالكتروني تتناسب مع الامكانيات المتاحة فالتربية النوعية هي التي تجعل من الإنسان قادرًا على رلى الإسهام في التنمية الاجتماعية المستدامة، لهذا فإن النوعية في التعليم تشكل شرط أساسي مسبق لإصلاح النظام التعليمي من أجل تمكين اقتصاد المعرفة من تطوير الواقع الاجتماعي الذي يعيشون فيه بجانب العامل الاقتصادي المتعلق بتقييم الاحتياجات التعليمية، وميزانية التعليم الإلكتروني، وكذلك تقييم التقنية المستخدمة، وبالتالي معرفة احتياجات الطلاب، ومعرفة احتياجاقم من أعضاء هيئة التدريس والموظفين، وبالتالي وضع معايير الجودة لتطوير تقنية التعليم الإلكتروني مثل: نشر تقنية إدارة المواد التعليمية، كما تعاني بعض الدول العربية من نقص التمويل اللازم لإنشاء بنية تحتية

تقنية مقارنة بالدول المتقدمة.

\subsection{7 الاختلافات المتعلقة باستراتيجيات التعليم الالكتروبي ومعاييره في دول المقارنة.}

- دول العالم الثالث تعتبر احد أهم المستهلكين للتقنية بجميع أنواعها.

- دول العالم المتقدم تسعي لتوظيف تقنية التعليم الالكتروين والاستفادة منها في بناء بحتمعات المعرفة وجعل جميع المؤسسات التعليمية مواكبة للحياة المعاصرة.

- - دول الاتحاد الاوربي ترى أن تقنية التعليم الالكتروني يمكن أن تساعد التعليم التقليدي في تلبية احتياجات التعليم العالي وليس بالضرورة أن تحل محله، المقصود من ذلك التعليم المدمج بين التقليدي والالكتروني.

تفسير أوجه الاختلافات المرتبطة باستراتيجيات ومعايير التعليم الإلكتروين. هناك العديد من القوى والعوامل الثقافية المرتبطة منها العامل الاجتماعي وهو غياب الثقافة الإلكترونية ووجود الأمية التقنية في المحتمعات العربية بشكل عام وعدم الوعي بالتعليم الإلكتروني، وإذا كان ذلك واضحًا في جميع مناحي الحياة في هذه البمتمعات فهو أكثر تأثيراً في النظم التعليمية العامل السياسي والمتمثل في ارتباط دول الاتحاد الأوروبي ببرامج مشتركة تعمل على التقارب في الاستراتيجيات والمعايير، بطريقة تساعد المؤسسات التعليمية على تقديم برامج التعليم الإلكتروني بالأسلوب الذي يحقق المعايير الأكاديمية، بحيث تحرص المؤسسة التعليمية على توفير برامج التعليم عن بعد من خلال 
توفير الفرص العادلة وبأسعار معقولة للطلاب للوصول إلى المستويات المطلوبة لاستكمال متطلبات التخرج، حيث يكون التعليم الإلكتروين نشاطًا يمارسه جميع المشاركين. فالعامل الاقتصادي، لا سيما ضعف الإمكانيات المادية، أو التكلفة العالية للحصول على العامل البشري المؤهل تعتبر إشكالية كبيرة من حيث تطوير استراتيجيات لتحقيق التطلعات المرغوبة.

2.7 أوجه التشابه والاختلاف بالاستفادة من أدوات التعليم الالكتروين في دول المقارنة. 1.2 .7 أوجه التشابه المتعلقة بالاستفادة من أدوات التعليم الالكتروبي في دول المقارنة. - - تتشابه جميع الدول المقارنة في تطبيقات تقنية التعليم الالكتروني من خلال الاستفادة من هذه التقنية في مؤسسات التعليم العالي والتعليم الذاتي، مثل تطبيقات الشبكات والانترنت والفصول الافتراضية و التطبيقات التربوية في بحال التعليم الالكتروني. - إصدار بعض القوانين واللوائح المنظمة للتعامل مع ادوات التعليم الالكتروين في دول المقارنة. تفسير أوجه التشابه المرتبطة بالاستفادة من أدوات التعليم الالكتروبي. يمكن تفسير أوجه التشابه المرتبطة بتطبيقات التعليم الإلكتروني من خلال القوى والعوامل الثقافية فالعامل الاجتماعي و المتمثل في وجود معايير وإجراءات قياسية لتحقيق الجودة في تطبيقات التعليم الإلكتروني، حيث يتم تحديد المعايير والإجراءات في كثير من الأحيان بواسطة خبراء التعليم الذين يعرفون الأدوات والمحددات المرتبطة بتطبيقات التعليم الإلكتروني، بالإضافة إلى العامل الاقتصادي الذي ساعد دول الاتحاد الأوروبي و الولايات المتحدة على الاستفادة من تقنية التعليم والمعلومات في معظم بحالات التعليم والتعلم الذاتي من البث التلفزيوني الفضائي الحاسوب و تطبيقات الانترنت و الاتصال الهاتفي والفاكس، بالإضافة إلى أدوات لتأمين مستوى معين من جودة التعليم، وبالتالي يعتمد التعليم

$$
\text { الإلكتروني على التقنية الرقمية و التي تقدم كخدمة إلكترونية. }
$$

2.2 .7 اوجه الاختلاوف المتعلقة بالاستفادة من أدوات التعليم الالكتروني في دول المقارنة . - ـ الدول العربية حديثة العهد بالتقنية تعاني من صعوبات عديدة في التعامل مع أدوات التعليم الالكتروني لأسباب عديدة سواء اقتصادية أو ثقافية أو اجتماعية.

- - الدول النامية كسنغافورة وكوريا الجنوبية بجحت في أن تتجاوز الحدود الزمنية والمكانية عند استخدامها

$$
\text { لأدوات التعليم الالكتروين. }
$$

- ـ - الدول المتقدمة كدول الاتحاد الاوربي التي قامت بعمل قاعدة كبيرة تستهدف محو الامية الالكترونية وبالتالي ايجاد قاعدة كبيرة تمكن من استخدام ادوات التعليم الالكتروين . 


\section{تفسير أوجه الاختلاف المرتبطة بالاستفادة من أدوات التعليم الالكتروبي.}

هناك العديد من نقاط القوى والعوامل الثقافية المرتبطة بأدوات التعليم التقني، منها العامل السياسي، وهو ارتباط دول الاتحاد الأوروبي ببرامج مشتركة تحقق كفايات تتعلق بأدوات التعليم الإلكتروني ومهارات استخدام الحاسوب وثقافة المعلومات ذات الصلة بالتعامل مع برامج الحاسوب التطبيقية من تحرير النص وإعداد العروض التقديمية، هذا بالإضافة إلى معرفة مكونات الحاسوب وأجزائه المختلفة، بالإضافة إلى تحقيق الكفاءات التي تتعامل مع برامج وخدمات الإنترنت مثل مهارات البريد الإلكتروني والمحادثة والدردشة ومهارات التصميم و الإنتاج والعمليات الفنية والتقنية. في المقابل، تعاني بعض الدول العربية من عدم موافقة ثقافة عناصر نظام التعليم الإلكتروني الأساسية مع متطلبات التقويم وفقًا لمعايير محددة وذلك على مستوى (المعلم والمتعلم والموظفين والإداريين وموظفي الدعم الفني)، وعدم ملاءمة الشروط الحالية للتقييم في نظام التعليم الإلكتروني وفقاً لمعايير الجودة الشاملة على مستوى التعليم الإلكتروين وأهدافه وأنماطه وبرابحه، إلى جانب العامل الاقتصادي يسبب العامل الاقتصادي فيما يختص بأدوات التعليم الالكتروين في عدم ملائمة جودة الخدمات التعليمية المقدمة إلى المتعلم في نظام التعليم الإلكتروني، مع مستوى جودة الخدمة التي تتوافق مع رغباته وتوقعاته وأساليب التقييم وكفاءة وفعالية نظام تقلديم الخدمة.

8. - 8 استراتيجية التحول الى برامج التعليم الالكتروني. التحول من التعليم التقليدي الى التعليم الالكتروني لابد له ان يتم بصورة تدريجية وفقا لاستراتيجية محددة الأهداف. خاصة في المحتمعات التي لم تزل فيها ثقافة استخدام الحاسوب وشبكاته متواضعة، فالتعليم الالكترويي يحتاج الى بنية أساسية لضمان مرونة التطبيق، ويقصد بالبنية الأساسية أجهزة الحواسيب وشبكات الحاسوب وخطوط الانترنت، فضلا عن المعامل التعليمية. وفي مقدمة متطلبات برامج التعليم الالكتروني هو شيوع ثقافة الحاسوب بين الكوادر التدريسية والطلبة على حد سواء. ابرزت الدراسة التحليلية المقارنة مدي التشابه والاختلاف بين الدول المتقدمة والتجارب النامية وكذلك بحاربنا العربية في بحال تطبيقات التعليم الالكتروني وفيما يلي تصور مقترح لتطبيقات التعليم الالكتروني في مؤسسات التعليم العالي في ضوء الدراسة التحليلية المقارنة .

1.8 البيئة التعليمية للتعليم الالكتروني في مؤسسات التعليم العالي: تتكون بيئة التعليم الالكتروين في المؤسسات التعليمية الجحامعية الي عدة مكونات اساسية وتشمل الآتي: متطلبات تقنية ومادية: توفير الإمكانيات المادية لتوفير بنية تحتية تشتمل على خوادم ومعدات وأجهزة قوية ذات سعة نطاق عالية، و مكونات بربحية: يتكون نظام التعليم الالكتروين من عدة أنظمة منها (نظام الدروس الالكترونية، نظام 
الاختبارات الالكترونية، نظام شؤون الطلبة، نظام ادارة المكتبات، نظام الدرجات والنتائج، نظام الحضور والانصراف، نظام البرامج الدراسية وتشمل الوسائط المتعددة) وتوفر شبكة إنترنت ذات سرعة عالية. مكونات بشرية: كوادر بشرية مؤهلة قادرة على التحكم بإدارة النظام وتصميم المقررات وإخراج المواد، وتدريب خاص للمحاضرين وللطلبة المشمولين بالنظام. ولو توفرت وتحققت جميع المتطلبات السابقة، فلا بد من توفر البيئة والتشريعات وخطة واضحة المعالم التي تدعم تنفيذ تطبيق التعليم الالكتروني، وتتمثل هذه البيئة بالوعي الكامل لضرورة وأهمية تنفيذ التعليم الالكتروين ابتداء من الإدارة العليا حتى الطلبة. الطالب: يجب ان يجيد مهارة التعلم الذاتي واستخدام الحاسب الآلي وكذلك الانترنت وتقنياتما.

\section{8}

يعتبر جعل التعليم الالكتروين جزء من برامج تحقيق جودة التعليم وكعنصر من أحد أهم عناصر الرؤية المستقبلية في تطبيقات التعليم الالكتروني، والعمل علي الاستفادة من بتارب الدول المتشاهة ثقافيا وحضاريا واقتصاديا مع الدول العربية وتطبيقها للتعليم الالكتروني، بمعني دراسة بحارب الدول النامية الأخرى المشابهة لنفس ظروفها والاستعانة بالخبراء منها مع الأخذ في الاعتبار الاطلاع علي ما هو جديد ومناسب في تحارب الدول المتقدمة عند التخطيط للتعليم الالكتروني .

بينت الدراسة التحليلية المقارنة مدي بحاح بجارب دول الاتحاد الأوربي في وضع استراتيجيات ساهمت في إيجاد بيئة مناسبة لتطبيقات التعليم الالكتروين وإيجاد قاعدة راسخة ساهمت في إبحاح تطبيقات التعليم الالكتروني، ومن ثم ضرورة تعاون الدول العربية مع بعضها البعض لتتبادل بث المناهج مما يخفض تكلفة استخدام التعليم الالكتروني في إطار الجودة. تحديد معايير قومية تتضمن المهارات الأساسية التي يتقنها المتعلم في التعليم العالي، وإعادة النظر في فلسفة وأهداف المناهج التعليمية، بجانب الاهتمام بضرورة ممارسة المتعلمين للأنشطة وتفاعلهم مع البيئة وذلك بتطبيق معايير مناسبة وحديثة لتصميم المباني المدرسية وتطويرها لتراعى جميع شروط البيئات التعليمية الجيدة التي تتيح التعلم الفعال والاستمرار في بناء المنشآت التي تساير التقدم التقني في العالم، وضرورة توظيف تقنية التعليم ومستحدثاتحا لخدمة المتعلم، والتركيز على الاستفادة بها في مناهج التعليم وبرابحه.

وضع استراتيجية متكاملة للتنمية المهنية لأعضاء هيئة التدريس والعاملين في بحال التعليم الالكتروني، وإنشاء جهاز على المستوى الوطني يتولى شئون التنمية المهنية وتشجيع جميع المهتمين بالتعليم الالكتروني على حضور المؤتمرات العلمية، وتنظيم ورش عمل وندوات تساهم في رفع مستواهم المهني بجانب الاهتمام بالجوانب التطبيقية والعملية في المناهج التدريبية لجميع المهتمين بتطبيقات التعليم الالكتروني، وإعادة النظر في المناهج الالكترونية للكليات والمعاهد لتفعيل أدورهم، وتحقيق التكامل بين التعليم الالكتروني والتقليدي. 


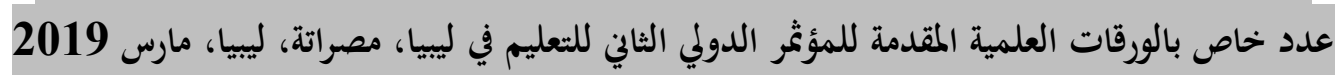

التأكيد على المشاركة المحتمعية لجميع القطاعات لمواجهة المشكلات التي تواجه التعليم الالكتروين، وتنظيم برامج لتوعية جميع أفراد المجتمع لعمل قاعدة تثقفيه للتعليم الالكتروين، وإنشاء صندوق لدعم وتطوير التعليم، بشكل يتيح مشاركة جميع الجهات العامة والخاصة والأفراد للمساهمة والمتابعة، فالمتطلبات الاستراتيجية معظمها تعتمد على إعادة تنظيم المواقف التعليمية وتدريب الأفراد وتوعيتهم ورفع كفاءاتم وتنميتهم مهنياً، وتوظيف التقنية المتاحة وإتاحة البيانات والمعلومات بسرعة وسهولة، وفضلا عما سبق يتطلب الأمر مراجعة مفهوم تقنية التعليم والذي اثبت أنه يمكن أن تساهم بدور بجانب إعداد الدراسات والأبحاث التي يتم من خلالها التوصل إلى طرائق وأساليب تعليمية جديدة، ونظريات وممارسات تؤدى إلى تحقيق جودة التعليم عند تطبيقها. هذا بجانب تقويم كفاءة الإجراءات والسياسات في كفاءة سير العمل بهذا البحلس، ومعرفة مدى استيعاب فريق الإدارة لصياغة السياسات وتطبيقها، والوقوف علي قدرتا علي الاتصال الخارجي وتطوير التعليم الإلكتروني وفقا للمستجدات المختلفة، وتشمل عملية التقويم للدعم الإداري التأكد من مدي اهتمام القيادة الإدارية في نظام التعليم الإلكتروين بالتخطيط، مدى تكوين علاقات عمل فعالة بين القيادة وكافة عناصر نظام التعليم الإلكتروني الأساسية، والتحقق من سياسة العمل الإداري لضمان فاعلية إدارة نظام التعليم الإلكتروني، وتوفر الإجراءات المناسبة لتقويم أداء الإداريين

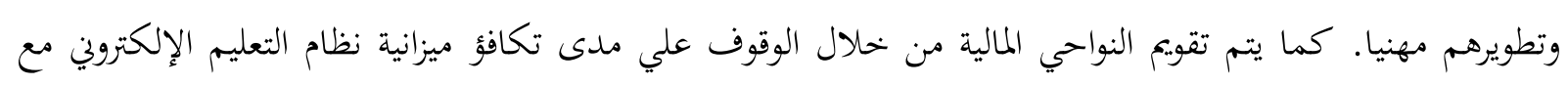
المؤسسات الأخرى المماثلة، بجانب التأكد من وجود نظام فعال للتقارير المالية والمحاسبية لدى نظام التعليم الإلكتروني، ويضاف إلي ذلك الوقوف علي مدى استثمار نظام التعليم الإلكتروني لمصادره ومتلكاته المالية والبشرية بطريقة جيدة، والوقوف علي مدى تحقيق الاستخدام الأمثل لمصادره المالية والبشرية .

بجانب ما سبق يمثل الاتصال الخارجي أحد الجوانب المهمة لتحديد مدي مساهمة أنشطة نظام التعليم الالكتروني في الرقي بالأوضاع الثقافية والاقتصادية وغيرها، ويتم تقويمه من خلال تعرف مدى تمتع النظام بعلاقات جيدة مع الجهات الإشرافية العليا، ومدى ارتباط نظام التعليم الإلكتروني بعلاقات فعالة مع الجهات الحكومية التي تتأثر بقراراها، ومدى قدرة نظام التعليم الالكتروني على تأمين مستوى مقبول من الدعم المالي من القطاع الخاص، وبالتالي تحقيق التطوير الذاتي لنظام التعليم الإلكتروني وتشمل مدى دعم نظام التعليم الإلكتروني لجهود الابتكار والإبداع، مدى توفر الاتحاهات الإيجابية نحو التطور الذاتي ·

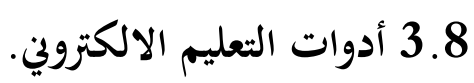

فيما يتعلق بأدوات التعليم الالكتروني يمكن توظيف التعليم القائم على التقنية بشكل فعال في العملية التعليمية وتصميم المواد والمناهج التعليمية وإنتاجها واستخدامها وتقويمها ومتابعتها، وتعرف الجديد أولاً بأول في بحال تقنية التعليم 
ومستحدثاتما، ودراسة كيفية الاستفادة منها وتوظيفها في العملية التعليمية، والاهتمام بالطالب والعناية به والحرص على تحقيق مستويات عالية من رضائه من خلال تحقيق احتياجاته ورغباته وتوقعاته. ولتوفير أدوات التعليم الالكتروي يجب التوسع في التعاون الدولي، من خلال الحرص على إقامة علاقات تبادلية مع الهيئات والمنظمات المختلفة على المستويين الإقليمي والدولي، بهدف ضمان جودة التعليم والاعتراف المتبادل بشهادات الاعتماد، وانطلاقا من التوجه للعمل على فتح آفاق العالمية أمام المؤسسات التعليمية الليبية، ويقوم مركز ضمان الجودة بعقد اتفاق تحالف مع المؤسسة الأوروبية لضمان جودة التعليم الالكتروني بمدف وضع نموذج مشترك لمعايير اعتماد مؤسسات التعليم العالي في مجال التعليم الالكتروني. يتم من خلال هذا التحالف منح المؤسسات الليبية التي تقدم كل أو جزء من برابجها من خلال التعليم الالكتروين. وبالنسبة للمقررات الإلكترونية كعنصراً رئيساً في منظومة التعليم الإلكتروني يمكن تصميمها علي الأسس والمبادئ العلمية التي تستند لمصادر مختلفة، كنظريات التعلم التي فسرت عملية التعلم وكيفية حدوثها، ووضعت مبادئ يمكن تطبيقها عند تصميم المواد التعليمية المختلفة، وكذلك نتائج الدراسات والبحوث السابقة، كما يعتمد علم تقنية التعليم على النظرية والتطبيق في تصميم المواد التعلمية وتطويرها واستخدامها وتقويمها؛ لكى تكون فعالة في تحقيق أهدافها، كما يمكن اعداد المقررات الالكترونية كمقررات دراسية يتم تدريسها وتقديمها او نشرها وتقييمها وإدارتا بشكل كامل عن طريق شبكة الإنترنت، حيث تتم كافة عمليات الاتصال والتفاعل بين المحاضر والطلاب من خلال الانترنت فقط، وهذا يستدعي أن تكون تقويم تلك العملية غير تقليدي بل ويمكن ان يطلق عليه التقويم الإلكتروني، والذي يتسم بكونه يتم سريعا وبشكل فوري حيث يمكن للمتعلم ان يشاهد نتيجة تعلمه في التو واللحظة، لذا تعتمد عملية تقويم المتعلمين في التعليم الإلكتروين على نمط محدد من التقويم والذي يعرف بالتقويم الإلكتروني ويقصد بالتقويم الإلكتروني العملية المستمرة والمنتظمة التي تمدف إلي تقييم أداء الطالب من خلال التعليم الالكتروني، مع التأكد من مساهمة الموارد المخصصة للعاملين في بحال الدعم التقني في جذب العناصر الجيدة للنظام، توافر الوسائل والأدوات الملائمة لتقويم أداء العاملين في بحال الدعم التقني. كما يمكن دعم تطبيقات التعليم الالكتروني من خلال فصول افتراضية او تخيلية، وهي فصول غير واقعية وتختلف جذريا عن الفصول التقليدية المستخدمة في التعليم التقليدي المتعارف عليه، بحيث يكون الفصل التخيلي هو فصل بكل المكونات والعناصر المتعارف عليها ففيه محاضر وطلاب ومادة تعليمية ووسائل ايضاح وامتحانات وتقييم وتكلفة مالية وقواعد وقوانين تحكم العملية التعليمية، الا انه لا يوجد فيه مكان واقعي، فهو عبارة عن موقع علي الشبكة الدولية الانترنت أو الشبكة المحلية الانترانت ويحتوي علي صفحات من المعلومات، وتوجد علي تلك الصفحات العناصر التعليمية التي سبق ذكرها وترتبط جميعها من خلال الشبكة، ويرتبط ايضا من خلال الشبكة بجميع المواقع الأخرى والتي تحتوي بطبيعة الحال علي فصول أخري تخيلية أو فصول أخرى حقيقية مرتبطة بالشبكة بها عدد محدود من الطلاب . 
تتفق الدراسة الحالية مع الدراسات السابقة من حيث التعامل مع أنواع مختلفة من تطبيقات التعليم الإلكتووني، سواء

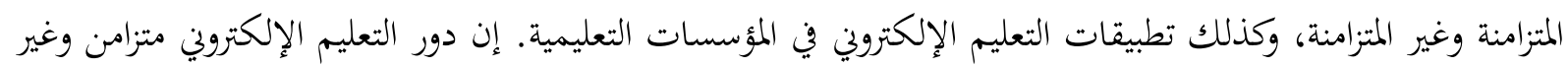

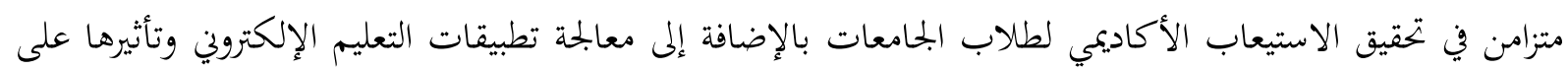

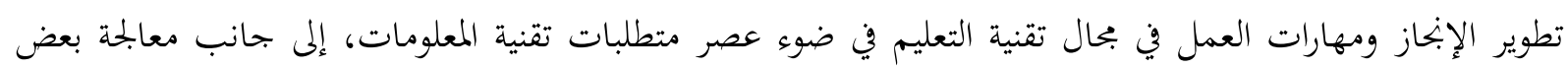
الجوانب المتعلقة بأعضاء هيئة التدريس وتفاعلهم مع التطبيقات التقنية، فضلاً عن الجوانب الإدارية المرتبطة بنجاح تطبيقات التعليم الإلكتروني، بالإضافة الى التعرف على أبرز التجارب الدولية في بحال تطبيقات التعليم الإلكتروني. تختلف الدراسة الحالية عن الدراسات السابقة فيما يتعلق بمعالجة تطبيقات التعليم الإلكتروني في ضوء بعض التجارب الدولية، بينما ركزت الدراسات السابقة على فعالية تطبيقات التعليم الإلكتروني في بعض المؤسسات التعليمية، أو معالجة

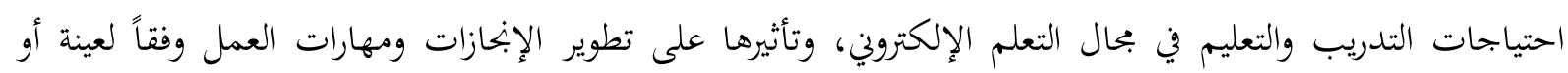

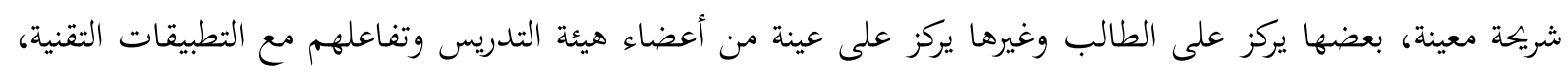

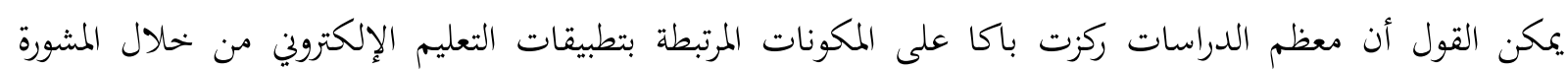
والمستخدمين دون معالجة التجارب الدولية للحكومة المؤسسية أو الرسمية. تعتمد الدراسة الحالية على الدراسات السابقة للتعرف على الإحصائيات والبيانات والمؤشرات المتعلقة بتتائج البحوث

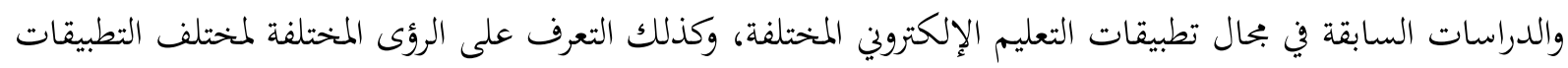
المرافقة لها، بالإضافة إلى دور التدريب في التعليم الإلكتروني، و تساعد هذه التطبيقات، مثل المتطلبات المادية والبشرية، في جعل تطبيقات التعليم الإلكتروني ناجحة، بالإضافة إلى التعرف على البيئات التعليمية لنجاح التعليم الإلكتروني.

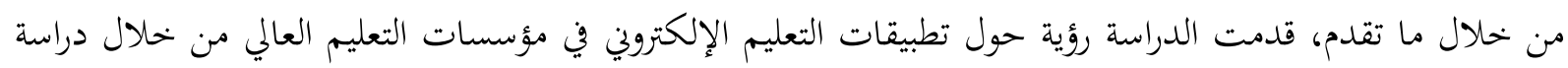
الاتحاهات والتجارب الحديثة لبعض الدول المتقدمة في هذا البحال من خلال مراجعة طرق التعليم الإلكتروني الحديث

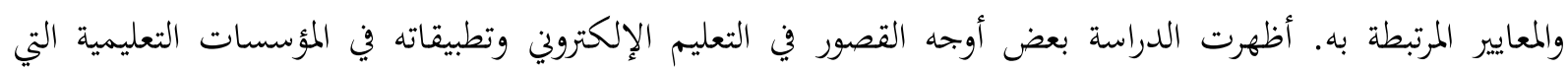
تتطلب الاستفادة من بعض الجوانب الإيجابية في التطبيقات الدولية المتعلقة بالتعليم الإلكتووني وأدواته في مؤسسات التعليم العالي في بعض الدول المتقدمة مثل الولايات المتحدة أو دول الاتحاد الأوروبي أو حتى البلدان التقدمية مثل سنغافورة وماليزيا التي تتناسب مع واقع وإمكانات بجتمعنا ومؤسسات التعليم العالي العربية. 


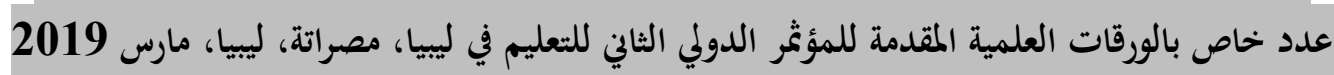

10. التوصيات:

نتيجة للتطور التقني السريع في جميع الميادين وخاصة في بحالات التعليم ، فإن الدور التقليدي لمؤسسات التعليم عامة والحامعات خاصة سوف يتغير قطعيا، وإن منظومة التعليم المعمول بها في جميع الجامعات سوف تكون كثر انفتاح بحيث تتبنى برامج وانظمة تعليم الكترونية متطورة تعطي نظام التعليم اهمية استراتيجية في بحتمعنا .

- - المؤسسات التعليمية: تغير انماط التعليم التقليدي بحيث تسطيع استيعاب اعداد كبيرة من الطلبة وتوفير الوقت والجها والمال للمؤسسة واستخدام انظمة ادارة التعليم الالكتروني بحيث تقلل من الاعباء الادارية لأعضاء هيئة التدريس في المؤسسة . مواد من كليات مختلفة في الجامعة). - عقد ورش عمل في الجامعة للطلبة والمدرسين تنفذها شركات متخصصة لتوضيح مفهوم التعليم الإلكتروني وأهميته، وكيفية إعداد المقررات وتطويرها. - توفير البنية التحتية، وتتمثل في إعداد الكوادر البشرية المدربة، وتوفير خطوط الاتصال السريع والأجهزة والمعدات ذات السرعة والتخزين العاليين. - - استقطاب الشركات العالمية المتخصصسة والتعاقد معها بهدف الاستفادة من خبراتها في بحال إعداد و تطوير مقررات إلكترونية.

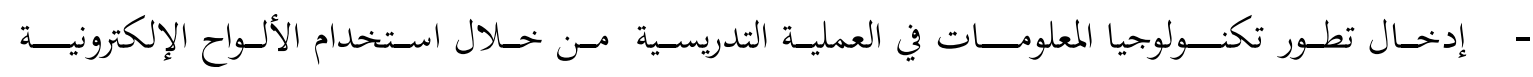
interactive whiteboard

\section{قائمة المراجع: \\ أولأ المراجع العربية: 2 - م}

بن فحوص، خالد أحمد. (2013).بعض الإبحاهات العالمية للتعليم العالى فى ظل العولمة ،بحلة التربية ، العدد 08 ، البحرين .

بلبكاي، جمال. (2015). التعليم الإلكتروني في ظل التحولات الحالية و الرهانات المستقبلية ، مداخلة ضمن المؤتمر

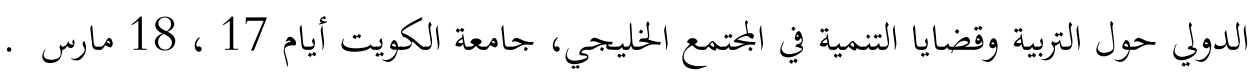


برغوتي،توفيق ، لويزة، مسعودي.(2016). التعليم الالكتروي في التعليم العالي تطبيقاته وتحدياته دراسة استكشافية بجامعة باتنة، مداخلة ألقيت خلال الملتقى الوطني لمركز جيل البحث العلمي حول تقنيات التعليم الحديثة المنظم

$$
\text { بالمكتبة الوطنيةالجزائرية، يوم } 20 \text { ديسمبر } 2016 \text { ـ }
$$

حسن، إسماعيل. (2018) .فاعلية التعلم التعاوني المصحوب وغير المصحوب بالتعلم الإلكتروني في تنمية التحصيل ومهارات العمل مع بحموعة في بحال تكنولوجيا التعليم لدى طالبات كلية التربية جامعة قطر "، بحلة التربية

$$
\text { للبحوث التربوية والنفسية والاجتماعية، العدد 125، الجزء الرابع، القاهرة. }
$$

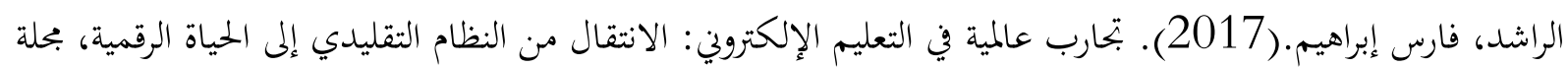

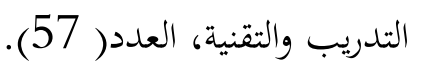

لازار، مهلدي .(2013).التعليم في قطر الواقع والافاق ،مركز الجزيرة للدراسات ، الدوحة ،صد5 . الصالح، بدر بن عبد الله .(2016). التعليم الإلكتروني والتصميم التعليمي شراكة من أجل الجودة، ورقة علمية مقدمة للمؤتمر العلمي العاشر للجمعية المصرية لتكنولوجيا التعليم الإلكتروني ومتطلبات الجودة الشاملة، كلية التربية،

$$
\text { جامعة عين شمس، القاهرة (5-7-7-7 -2016). }
$$

الصالح ، بدر. (2017):التعليم الجامعي الافتراضي (دراسة مقارنة لجامعات عربية واجنبية افتراضية مختارة.)بحلة كليات

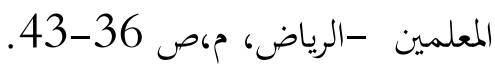

غراف ، نصر الدين .(2014). التعليم الالكتروني ومستقبل الإصلاحات بالجامعة الجزائرية ، بحلة RIST البحلد العدد

الفالح ، مريم • (2018). فاعلية برنامج تدريبي على الإنترنت لتنمية الجوانب المعرفية لكفايات التعليم الإلكتروين لدى عضو هيئة التدريس بجامعة الرياض للبنات ,المؤتمر العلمي السنوي الحادي عشر للجمعية المصرية لتكنولوجيا التعليم" تكنولوجيا التعليم الإلكتروني وتحديات التطوير التربوي في الوطن العرب، كتاب المؤتمر، القاهرة. نوفل، محمد نبيل.(2016). الجامعة والمحتمع في القرن الحادي والعشرين ،المحالة الثاني والعشرين ، العدد 01 ، المنظمة العربية للتربية والثقافة والعلوم ، تونس.

\section{ثانيا المراجع ألأنجليزية:}

Asunka, S.(2017). Online learning in higher education in sub-Saharan Africa: Ghana Experiences and perceptions of university students, International Journal of Search in Open and distance learning, New York, P12-29.

Dutto, W. (2016). New Media and Institutions of Higher Education. London, P.8.

Jung, I. (2017) The issue of Regional Focus Changing Faces open and distance education in Asia, Aerodl Asia

Regional Editor The current state of e-learning strategies and enhance the competitiveness of Education in Higher Education Korea, Korea, PP.15-21.

Medved, JP. (2014). Top 10 eLearning statistics for 2014, Articles on https://elearninginfographics.com, access on 20-12-2018 